\title{
Repensando o Ensino de Cultura em Mulas de Língua Estrangeira
}

\author{
Rethinking the Teaching of Culture \\ in Foreign Language Classes
}

\section{Ulrike Agathe SCHRÖDER * Milene Mendes de OLIVEIRA **}

Resumo: Estabelecendo um diálogo com o artigo "A necessária integração da língua e cultura no ensino de língua estrangeira" de autoria de Klondy Lúcia de Oliveira Agra e Odete Burgeile (2010), este texto enfatiza algumas observações feitas pelas autoras e sugere novas reflexões para o ensino da cultura em sala de aula. Não temos por objetivo propor um método de ensino específico, mas sim problematizar o ensino de questões culturais em aulas de língua estrangeira. Propomos que um ensino reflexivo de cultura em aulas de língua estrangeira pode contribuir para a formação de um ser crítico, capaz de pensar a sua própria cultura e a cultura de outros povos. O ensino de uma nova língua ganha, portanto, um novo patamar. Não é o mero ensino de estruturas linguísticas ou mesmo de hábitos culturais relativos à L2; trata-se, sim, de um caminho para a descoberta de novas visões de mundo que, em interação com o conhecimento de cada um dos aprendizes, os conduz a novas experiências.

\footnotetext{
* Possui doutorado em Comunicação Social (2003) e mestrado em Comunicação Social, Germanística, Psicologia - Universität Essen-Gesamthochschule (1999). Atua como Professora Adjunta III na Universidade Federal de Minas Gerais, Faculdade de Letras. Contato: schroederulrike@gmx.com

** Aluna do mestrado em Estudos Linguísticos na Universidade Federal de Minas Gerais. Possui especialização em Ensino de Inglês pela Universidade Federal de Minas Gerais (2010) e graduação em Licenciatura em Língua Inglesa pela Universidade Federal de Ouro Preto (2006). Contato: mimamendes@yahoo.com.br
} 
Palavras-chave: Língua e cultura. Ensino de cultura. Estudos Interculturais.

Abstract: By engaging in a dialogue with the article "A necessária integração da língua e cultura no ensino de língua estrangeira”, by Klondy Lúcia de Oliveira Agra and Odete Burgeile (2010), this paper emphasizes some observations made by the authors and suggests new reflections for the teaching of culture in foreign language classes. We do not aim to propose a new teaching method, but we do intend to raise new questions about the teaching of cultural aspects in foreign language classes. We propose that a reflexive teaching of culture in foreign language classes can contribute to establishing learner`s sensibility to their own and other people`s culture. Thus, the teaching of another language gets to a new level. It is not the mere teaching of linguistic structures or even cultural habits related to the foreign language, but a path towards the discovery of new world views that interact with learners' previous knowledge and guide them to new experiences.

Keywords: Language and culture. Teaching of culture. Intercultural Studies.

\section{Introdução}

O presente trabalho tem por objetivo estabelecer um diálogo com outro artigo, publicado por esta mesma revista, intitulado "A necessária integração da língua e cultura no ensino de língua estrangeira”, de autoria de Klondy Lúcia de Oliveira Agra e Odete Burgeile (2010). Neste trabalho, as autoras se propõem a discutir como uma comunicação efetiva em uma língua estrangeira depende não apenas do conhecimento da língua, em seu sentido estrutural, mas também do conhecimento da cultura dos países que têm a língua estrangeira como primeira língua.

A argumentação que pretendemos construir será assim dividida: em um primeiro momento, apresentaremos um breve panorama do surgimento e do desenvolvimento do interesse pela conexão entre língua e cultura que, atualmente, tem sua expressão mais significativa no crescimento dos estudos interculturais. Em um segundo momento, 
em consonância com Agra e Burgeile (2010), defenderemos o estudo da cultura nas aulas de língua estrangeira. Posteriormente, proporemos uma extensão da discussão e trataremos da formação do aprendiz como ser crítico, (auto)consciente e atento não apenas à cultura do outro, mas também à própria cultura. Em seguida, discorreremos sobre atividades que podem vir a servir a esse propósito e faremos as considerações finais.

\section{Dos estudos da Linguística Antropológica ao ensino da língua estrangeira}

Junto às abordagens românticas de Herder (2002) e Humboldt (1992), o interesse pela relação entre língua e cultura nasceu no contexto histórico do início da formação dos Estados Nacionais, no final do século dezoito e na primeira metade do século dezenove. A partir dos trabalhos desses estudiosos, no começo do século vinte, surgiu a vertente norte-americana da Linguística Antropológica. Nos seus estudos empíricos voltados para a análise da relação entre visão do mundo e estrutura da língua em comunidades indígenas nos Estados Unidos, Boas (1982), Sapir (1949) e Whorf (1956) retomaram as ideias das abordagens alemãs, transformando-as em prática. Finalmente, com o advento da Sociolinguística nos anos sessenta e setenta, o foco mudou da estrutura de uma língua para o seu uso; ou seja, maior ênfase foi dada a um entendimento da língua como ação encaixada em um contexto sociocultural específico.

Um dos primeiros a se dedicar ao processo da comunicação intercultural por meio de uma análise microanalítica foi o fundador da Sociolinguística Interacional John Gumperz, segundo o qual os participantes, em situações comunicativas, usam pistas de contextualização (GUMPERZ, 1982, p. 31), indicando, em uma situação concreta, suas próprias definições da situação por meio de tais pistas. A elas pertencem, por exemplo: a cinesia e a proxêmica; a prosódia (como altura, velocidade, ritmo, acentuação etc.); o comportamento do olhar; a colocação temporal (como intervalos ou simultaneidade do falar) e a escolha de variantes e formulações linguísticas (AUER, 1986, p. 26). Com ajuda de tais pistas, esquemas do conhecimento sobre a natureza e desenvolvimento de diferentes tipos de interações 
são colocados à disposição e, através deles, os interlocutores, geralmente, criam um quadro de interpretação compartilhado dentro de uma situação dada. Porém, como as pistas de contextualização são adquiridas e convencionalizadas em contextos comunicativos da própria cultura e, por conseguinte, funcionam de forma natural, sem serem questionadas, elas se esquivam da condução consciente, tornando-se fonte de 'mal-entendidos' na comunicação intercultural. Esses estudos pioneiros de Gumperz contribuíram para um crescimento recente de estudos no campo da comunicação intercultural e para o surgimento de uma subdisciplina dentro da pragmática, a saber, a 'pragmática intercultural' (SCHRÖDER, 2011), que chama muita atenção no campo dos estudos do ensino da língua estrangeira por direcionar o interesse a questões de 'transferência pragmática' (FIENEMANN; REHBEIN, 2004).

Essas influências tiveram um efeito significativo no ensino da língua estrangeira. Depois do paradigma comunicativo que, até hoje, se reflete nos livros didáticos, cresce a percepção de que é necessário integrar aspectos culturais e cognitivos novamente. Competência da língua, agora, é definida como competência cultural, uma vez que não é possível separar habilidades linguísticas de habilidades não verbais (motoras, auditivas, visuais), que também são de cunho cultural. A focalização predominante na competência produtiva é completada por competências da compreensão e interpretação (OKSAAR, 2003, p. 28-38). Neste contexto, o novo é sempre identificado com o já conhecido: "O indivíduo sempre enfrenta tudo o que é novo com sua experiência” (OKSAAR, 2003, p. 33). ${ }^{1}$

White (1997 apud SPENCER-OATEY, 2005) e Thomas (1983 apud SPENCER-OATEY, 2005) tratam da questão das convenções pragmalinguísticas. Estas se referem a convenções de usos estratégicos da linguagem que afetam a maneira como um sentido pragmático é entendido em um contexto determinado. Spencer-Oatey (2005) cita um exemplo apresentado por White (1997), que relata que, em um

\footnotetext{
${ }^{1}$ Nossa tradução de: "Ein Individuum steht allem Neuen mit seiner Erfahrung entgegen".
} 
hotel na Coreia, ele se dirigiu à recepção para relatar um defeito no telefone de seu quarto. A recepcionista, após entrar em contato com as pessoas responsáveis por esse serviço, disse ao hóspede: "I think you had better wait in your room”. Segundo White, em um contexto britânico, esse tipo de estrutura linguística seria mais apropriadamente utilizada por uma autoridade com o poder de fazer recomendações a pessoas em posição subordinada, o que não se aplica à relação hóspederecepcionista, pelo menos em contexto britânico. Houve, portanto, um 'erro' pragmalinguístico; ou seja, uma assimetria entre a formulação linguística escolhida pela recepcionista e o sentindo que ela, provavelmente, queria imprimir à frase. Parece-nos que Agra e Burgeile (2010) apresentam, também, esse tipo de preocupação. Para elas, no caso da impossibilidade de construir sentidos na língua alvo, "o aprendiz [...] pode cometer enganos e mal-entendidos que, geralmente, o impelem a desconfortos perante os falantes nativos da língua" (AGRA; BURGEILE, 2010, p. 22).

Como professoras de língua estrangeira, constantemente presenciamos situações de mal-entendidos potenciais, que são resguardados apenas pelo contexto de sala de aula onde o aprendiz está inserido. Há, por exemplo, situações em que o aluno requer que uma explicação seja repetida e, para isso, utiliza-se do imperativo "Repeat" recorrendo à entonação de pergunta do Português Brasileiro, ao invés do "Could you repeat, please?". Em outras culturas, como a norte-americana, por exemplo, o uso do modo imperativo poderia acarretar interpretações assimétricas, por parte dos interlocutores, acerca da natureza da interação em questão. O que está por trás dessa diferença é o fato de que culturas com maior tendência ao individualismo conferem maior valor cultural à autonomia dos indivíduos (WIERZBICKA, 2003, p. 72-78), que se reflete na língua, por exemplo, por meio de expressões que distanciam um interlocutor do outro evitando, dessa forma, a 'invasão' do espaço do outro ${ }^{2}$. Por conseguinte, em Inglês, o uso direto de imperativos é bastante limitado e substituido

${ }^{2}$ A esse respeito, conferir a Teoria da Polidez (BROWN; LEVINSON, 1987). 
pela forma interrogativa que se reflete nas fórmulas dos assim chamados whimperatives, como "Would you do X?", que podem ser vistos como atos de fala indiretos. Sendo assim, a autonomia do indivíduo é preservada (ou seja, ele tem maior liberdade para aceitar ou negar o pedido) e a força ilocucionária é atenuada.

Todavia, mesmo que a didática comunicativa busque integrar questões pragmáticas ao ensino de língua estrangeira, os livros didáticos apresentam os contextos social e cultural, muitas vezes, separadamente do uso da língua. Sendo assim, é comum que, por exemplo, as diferenças nos atos de fala apareçam apenas de modo implícito, junto a fórmulas que são usadas em situações comunicativas específicas e prototípicas de como 'se fazer um pedido no restaurante', 'comprar roupa', 'consultar um médico' ou 'se fazer, aceitar ou recusar um convite', que é o caso do exemplo que se segue.

No livro International Express ${ }^{3}$, dedicado ao ensino de Inglês para negócios; mais especificamente, na unidade "Crossing Cultures" (p. 74-81), a autora apresenta questões relevantes sobre diferenças culturais, especialmente no que diz respeito a estratégias de polidez. Grande parte das discussões apresentadas nesta unidade trata de diferentes hábitos comportamentais em diversas culturas, como questões relativas a pontualidade, informalidade entre colegas de trabalho e proxêmica. Entretanto, é perceptível que a autora trata de aspectos culturais e linguísticos isoladamente; ou seja, não é possível notar, no livro, uma conexão entre aspectos culturais e aspectos linguísticos dos países citados na unidade. O conceito de cultura é claramente isolado do conceito de língua. Exemplo disso é a sessão "Focus on Functions", que trata de como se fazer convites e como se aceitar ou rejeitar convites em Inglês. Temos aqui uma abordagem bastante tradicional.

No exercício número 3, o aluno deve ouvir duas conversas de telefone e marcar as frases que ouviu na gravação. As opções são estas:

${ }^{3}$ Student's Book - Pre-Intermediate. 


\section{Inviting}

I'd like to invite you to...

Would you join us...?

Would you like to...?

How about...?

\section{Accepting}

Thank you. I'd be delighted to accept.

Thank you. I'd love to.

Thank you. I'd enjoy that.

\section{Declining}

I'd love to, but (I'm afraid I can't).

Thanks a lot, but (I've made another arrangement).

(TAYLOR, 2007, p. 81)

Em seguida, os alunos devem usar as frases do exercício 3, para realizar uma prática oral das funções ensinadas:

\section{Student A}

Student B

\section{Situation 1}

[1] Invite your colleague to join you

for lunch tomorrow.

[3] Suggest another day next week.

[2] Decline and give a reason.

[4] Accept.

\section{Situation 2}

[1] Invite your colleague for a drink after work.

[2] Decline and give a reason.

Suggest another day

[3] Accept.

(TAYLOR, 2007, p. 81) 
Assim, é possível notar que as comparações culturais apresentadas nessa unidade cessam quando acontece a exposição de aspectos funcionais da língua inglesa. Na nossa visão, esta seria uma oportunidade interessante para que comparações pragmalinguísticas interculturais fossem feitas. Poderia ser tematizada, por exemplo, a questão de culturas mais diretas/indiretas ou individuais/coletivistas etc.. Todavia, concomitantemente a isso, os alunos teriam que ser sensibilizados para os fatos de que até tais categorias bipolares são apenas abstrações e de que, de modo geral, uma comparação concreta - por exemplo, Brasil versus Estados Unidos - depende muito do gênero comunicativo ao qual ela se refere. Apenas nesse âmbito mais específico é possível julgar se os padrões linguísticos aplicados são mais diretos ou mais indiretos.

Ainda no campo das inconsistências pragmáticas interculturais, é possível que um brasileiro, ao falar a língua inglesa, em um restaurante, em um país estrangeiro, tente chamar um garçom utilizando-se da expressão amplamente usada no Brasil, para esse fim - "Garçom!" , que ele, provavelmente, traduziria como "Waiter!". Nos Estados Unidos e na Inglaterra, por exemplo, isso seria extremamente rude. Uma maneira educada de chamar a atenção do atendente seria dizer "Excuse me". No Brasil, o correlato "Com licença", em alguns contextos mais informais, poderia soar um pouco estranho.

É importante enfatizar que essa tendência não é apenas um problema no ensino de Inglês como LE, mas pode ocorrer, também, no ensino de outras línguas. Analisaremos, agora, um exemplo em que traçamos uma comparação entre introduções de telefonemas prototípicas, como geralmente ocorrem na Alemanha e no Brasil, que ilustram bem como as convenções pragmalinguísticas podem resultar em mal-entendidos, caso não sejam analisadas a fundo. No que diz respeito a conversas telefônicas, Johnen (2001, p. 123-124) observa que, no caso brasileiro, a identificação dos dois participantes em um telefonema ocorre apenas após a parte introdutória e somente depois que aquele que recebeu o telefonema tenha perguntado, a quem telefonou, pelo nome dele, o que implica o uso de verbos modais como gostaria de ou desejar. Na Alemanha, uma vez que a identificação já ocorre por parte de quem telefona, isso não é necessário. Se quem foi chamado esquece o nome de quem ligou ou não o ouviu, outras 
fórmulas roteirizadas são aplicadas. Uma comparação ilustra essa diferença:

Introdução prototípica brasileira

A: Alô.

B: Alô. O Ricardo está?

A: Quem gostaria?

B: É Sandra

A: Um momento, por favor [...] ele está em outra ligação. Quer ligar mais tarde?

B: Então, ligo mais tarde. Obrigada.

Introdução prototípica alemã

A: Schönen guten Tag, Schulte am Apparat. Könnte ich Herrn Schmitz sprechen?

(A: Bom dia, meu nome é Schulte. ${ }^{4}$ Poderia falar com o Senhor Schmitz?)

B: Herr Schmitz ist gerade zum Mittagessen raus. Kann ich ihm eine Nachricht hinterlassen?

(B: O Senhor Schmitz está almoçando agora. Posso deixar um recado para ele?)

A: Ja, vielleicht könnten Sie ihm mitteilen, dass ich noch bis 17:00 Uhr unter meiner Büronummer erreichbar bin.

(A: Sim, talvez a senhora poderia dizer a ele que ainda estou acessivel no meu número de escritório até 17:00h?)

B: Wie war Ihr Name noch, bitte?

(B: Como é o nome da senhora mesmo, por favor?)

A: Schulte.

(A: Schulte.)

B: Alles klar, Frau Schulte. Ich werd's ihm ausrichten.

(B: Tudo bem, Senhora Schulte. Vou passar o recado para ele.)

${ }^{4}$ Sobrenome alemão. 
Essas convenções distintas ilustram que um alemão, para quem um brasileiro telefona na Alemanha, pode interpretar o procedimento brasileiro como 'grosseiro', por uma série de motivos. Caso o brasileiro transfira seus passos da rotina conversacional brasileira ao contexto alemão, a pessoa será chamada pelo seu primeiro nome, aspecto até bem abordado no ensino do Alemão como língua estrangeira, de modo que o brasileiro deve saber que, na Alemanha, as pessoas da vida pública, de modo geral, são chamadas pelo sobrenome. Todavia, há mais fatores aqui que podem causar essa impressão, sem que o aluno brasileiro tenha consciência disso: o brasileiro não se apresenta, mas pergunta, imediatamente, pela pessoa com a qual ele gostaria de falar. Há dois aspectos importantes aqui com relação às estratégias de polidez (BROWN; LEVINSON, 1978): a) obviamente, os pares adjacentes (SACKS; SCHEGLOFF 1974) são invertidos: enquanto que, em Alemão, a pessoa que liga, concomitantemente, se apresenta, no Brasil, é a pessoa que atende que se apresenta primeiro; b) o uso do condicional (poderia) e do adverbial (talvez) atenua o pedido da Senhora Schulte. Não obstante, essa conexão entre a fala e a cultura é raramente feita em livros didáticos do ensino da língua estrangeira. Em Blaue Blume, livro didático que se direciona exclusivamente a brasileiros, há pelo menos uma tematização da questão da polidez na lição 21 (EICHHEIM et al., 2006, p. 132-134). Contudo, como o livro explicitamente se opõe à abordagem comunicativa, apesar de ter uma abordagem reflexiva que busca conscientizar o aluno, a escolha de textos quase exclusivamente do campo literário impede que o aluno lance uma ponte entre a teoria e a prática.

\section{Ensino da conexão entre cultura e língua como processo crítico e (auto)reflexivo}

Concordamos, portanto, com a afirmação de Agra e Burgeile (2010, p. 22) que diz que "o ensino de LE requer que, tanto em turmas iniciais, quanto em turmas de estudos avançados, os hábitos culturais sejam integrados ao estudo dessa língua." Entretanto, gostaríamos de propor uma visão diferenciada para o fenômeno de 'absorção' de valores culturais que as autoras apresentam na continuação do excerto supracitado: "Só assim o aprendiz terá o tempo necessário para absorver os valores culturais e os hábitos que os refletem" (grifo nosso) (AGRA; 
BURGEILE, 2010, p. 22). A nosso ver, a maneira pela qual nos relacionamos com a cultura-alvo deve ser mais criticamente analisada, pois se trata de uma relação complexa, que não pode ser reduzida a atividades mecânicas de aprendizagem. Logo, não deveria ser nosso objetivo simplesmente 'passar' os valores culturais aos nossos alunos, como se fossem um conhecimento objetivo e monolítico.

Acredita-se, por exemplo, que muitos professores brasileiros de LE pregam a primazia linguística e cultural das línguas que ensinam em detrimento da língua portuguesa e da cultura brasileira. A nosso ver, o ensino de cultura não deve legitimar a crença, altamente difundida, de que o professor de LE é um profissional alienado, que difunde a língua e a cultura dos países que têm a LE como língua materna de maneira acrítica ou até mesmo tendenciosa.

A esse respeito, Cox e Assis-Peterson argumentam que professores de língua estrangeira, mormente aqueles de língua inglesa, permanecem à margem desse movimento [pedagogia crítica], sendo inúmeras vezes rotulados de alienados, acríticos, apolíticos, reacionários, partidários da direita, agentes do imperialismo americano, pelegos [...]. Entre os intelectuais politizados, o professor de inglês é suspeito de ter "vendido a alma para o diabo". (COX; ASSIS-PETERSON, 2001, p. 17)

Apesar de seu livro Resisting Linguistic Imperialism in English Teaching tratar, especificamente, do ensino de Inglês em comunidades periféricas, Canagarajah (2003) apresenta ao leitor algumas informações reveladoras sobre o ensino de LEs em geral. Para ele,

Muitas das estruturas e práticas da educação no mundo moderno são fruto de filosofias educacionais e tradições pedagógicas que são remanescentes da missão colonial de difundir valores do Iluminismo para propósitos civilizatórios. ${ }^{5}$ (CANAGARAJAH, 2003, p. 12)

${ }^{5}$ Nossa tradução de: "many of the structures and practices of schooling in the modern world are built on educational philosophies and pedagogical traditions which can be traced back to the colonial mission of spreading Enlightment values for civilizing purposes". 
$\mathrm{O}$ autor ressalta, ainda, que a língua inglesa pode abarcar valores culturais e ideológicos totalmente alheios a algumas comunidades. Para ele, os materiais didáticos têm orientações altamente anglófonas, que podem não se mostrar apropriadas para alguns tipos de contexto. $\mathrm{O}$ livro American Inside Out-Upper Intermediate - Student's book (KAY; JONES, 2003) traz temas como a febre do ouro de 1849, relações entre mães e filhos adolescentes, beleza física, dietas, revolução digital, que, embora sejam de interesse de muitas pessoas de diferentes culturas, são apresentados de acordo com uma perspectiva unicamente norteamericana. Não há preocupação clara em se abrir espaço para os diferentes pontos de vistas que possam emergir de outras culturas.

Entretanto, mesmo que um professor faça uso de um livro como o supracitado, ele pode optar por um enfoque intercultural, que incentiva a discussão dos próprios padrões culturais e dos padrões culturais dos povos que têm a LE como L1. Assim, ele dá voz ao aprendiz e o faz refletir sobre as semelhanças e dessemelhanças entre a sua cultura e a do outro e permite, ainda, que ele se aproprie do novo conhecimento e não, necessariamente, que o "absorva".

A abordagem reflexiva e cognitiva promove a ideia de criar uma 'posição entre as culturas', noção que remonta a Mühlmann (1956) e Gadamer (1960). O último chamou este espaço da interculturalidade como o "verdadeiro lugar da hermeneûtica" (GADAMER, 1960, p. 279). Mais tarde, Casmir (1978) fala de 'third culture': trata-se de uma conscientização que possibilita uma relação recíproca, transformando o alheio em algo familiar e o familiar em algo contingente; é um processo em que a pessoa assume uma posição reflexiva que abre espaço para uma perspectiva distante de modo que o alvo seria uma oscilação entre pontos de vista distintos.

Similarmente, ao tratar da interação entre novos conhecimentos e o conhecimento prévio, Wertsch (1991; 1998 apud BLOCK, 2003) liga o termo apropriação à palavra russa prisvoit, usada por Bakhtin (1981 apud BLOCK, 2003), que significa 'o processo de se apoderar de alguma coisa que pertence a outro fazendo dessa coisa sua propriedade’. Segundo Block (2003), Wertsch e Bakhtin não veem a apropriação como um processo individual e interno; ao contrário, ela é semelhante àquilo que teóricos interessados por questões relativas a cultura e a identidade têm chamado de 'terceiro lugar' (third place). Portanto, a 
apropriação não é passar do externo para o interno; é, na verdade, o encontro do externo e do interno, para formar um novo estado. Logo, a apropriação de práticas culturais leva o aprendiz a usar o seu conhecimento prévio, oriundo de sua cultura, para entender e acomodar o novo conhecimento que lhe está sendo apresentado. Porém, não é apenas o conhecimento novo que se acomoda e se ajusta ao conhecimento prévio; o próprio conhecimento anterior do aprendiz sofre uma 'perturbação' e pode se reajustar.

Nessa conjuntura, é fundamental enfatizar a importância do professor de LE como aquele que pode iniciar uma reflexão e guiar o aluno à descoberta de novas maneiras de se conceitualizar o mundo, entrando em contato com outras visões de mundo (Weltsichten), no antigo sentido de Humboldt (1992, p. 60), que já havia constatado: "Por conseguinte, a aprendizagem de uma língua estrangeira deveria ser a obtenção de um novo ponto de vista dentro da visão do mundo existente"

Caso o professor opte por apresentar os conteúdos de maneira a encorajar a discussão e a análise contrastiva da nova cultura e da cultura do país de origem dos aprendizes, ele pode agir como facilitador de um processo de formação de um indivíduo crítico e consciente; um indivíduo que busca conhecer uma nova língua e, consequentemente, uma nova cultura, mas que reconhece o valor da sua própria.

\section{Ilustrações da conexão entre língua e cultura em sala de aula}

Agra e Burgeile (2010) apontam o drama como atividade que por trabalhar com a linguagem verbal e não verbal e ainda ser capaz de incentivar a empatia com relação a outras culturas - pode desenvolver, nos alunos, a compreensão intercultural. As autoras

${ }^{6}$ A esse respeito, conferir Maturana e Varela, 2004.

${ }^{7}$ World View. A esse respeito, conferir Palmer, 1996.

${ }^{8}$ Nossa tradução de: "Die Erlernung einer fremden Sprache sollte daher die Gewinnung eines neuen Standpunktes in der bisherigen Weltansicht seyn". 
sugerem também um trabalho com filmes, desenhos e músicas estrangeiras. Agra e Burgeile (2010, p. 25) apontam que "filmar a encenação dos seus alunos e, depois, corrigir hábitos culturais é, também, um bom modo de aprender sobre o outro e internalizar padrões culturais". Temos algumas ressalvas com relação à 'correção' de hábitos e 'internalização' de padrões culturais. Sugerimos que, ao invés de 'corrigir' os hábitos culturais dos alunos, o professor utilize-se de gravações desse tipo como forma de incitar discussões a respeito de como os nossos hábitos verbais e não verbais são capazes de refletir aspectos culturais do nosso país ou da nossa comunidade. Em seguida, o professor poderia fazer uma comparação sobre como a língua estrangeira faz o mesmo com relação aos aspectos culturais dos países de onde a língua provém.

Block (2003) cita um exemplo de trabalho que explora as diferenças culturais entre a língua materna e a LE. Liddicoat e Crozet (2001 apud BLOCK, 2003) trabalharam a questão da interculturalidade e da apropriação de artefatos culturais com aprendizes australianos de Francês. Antes de proporem a atividade em sala de aula, analisaram a aquisição de funções simples, como perguntar e responder sobre o fim de semana ('- How was your weekend? - Fine') na Austrália e na França. Eles chegaram à conclusão de que as funções de cumprimentos variam, pragmaticamente, em línguas e culturas distintas. Na versão francesa, a pergunta torna-se uma oportunidade para transferência de informação e estreitamento de laços de amizade, enquanto que a versão australiana da pergunta configura-se mais como uma rotina de conversação com pouca importância para o fortalecimento de relações interpessoais.

Em seguida, Liddicoat e Crozet (2001 apud BLOCK, 2003) se propuseram a examinar se os aprendizes mudariam as suas respostas depois de participar de atividades que despertassem a consciência a respeito das diferenças entre como falantes de Francês e falantes de Inglês australiano reagem à pergunta sobre o fim de semana. Os linguistas notaram que aprendizes expostos a uma análise sociocultural do Francês e do Inglês manifestaram mudanças na maneira através da qual eles lidavam com a pergunta 'bow was your weekend?'. Entretanto, os autores notaram também que o procedimento adotado levantou outra 
questão interessante: alguns alunos se mostraram relutantes em falar 'como os Franceses'. Liddicoat e Crozet (2001) concluíram que os alunos desenvolveram a compreensão de que aprender a falar uma LE não é apenas uma questão de simplesmente adotar normas de comportamento da língua, mas, também, uma questão de achar uma acomodação aceitável entre a primeira cultura do aprendiz e a cultura da língua-alvo.

Portanto, uma tematização de aspectos da relação entre língua e cultura, a nosso ver, não deveria ter em vista a mediação de um alto número de valores culturais e práticas do uso da língua estrangeira, mas sim, voltada para uma abordagem cognitiva e reflexiva, sensibilizar para a percepção da conexão entre cultura, cognição e comunicação e sua variedade, em dependência de contextos específicos do uso. Um exemplo de uma operacionalização da interpenetração de língua e cultura que inclui um olhar reflexivo é dado por Schröder (2006), que mostra como alunos podem ser sensibilizados pela relatividade cultural no uso de metáforas cotidianas - fenômeno, geralmente, altamente inconsciente. Uma atividade em que alunos têm que descobrir que imagens estão por trás de certas expressões como "O amor inclui o desejo da carne" - expressão metafórica comum no Brasil - ou "nossa relação amorosa não funcionava mais" - expressão metafórica comum na Alemanha -, extraídas de entrevistas autênticas com alemães e brasileiros, não apenas sensibiliza pelo uso divergente e pelo alcance distinto de tais expressões metafóricas, mas possibilita também um olhar distante com relação à própria cultura e às suas conceitualizações contingentes.

Diana Boxer (2002) enfatiza a importância de pesquisas e práticas educacionais que levem em consideração as visões de mundo de duas ou mais culturas. Para ela,

Se duas línguas, juntamente com os dois domínios culturais que elas expressam, não são mantidos separados em uma troca intercultural complexa, a mais fraca das duas culturas nesse contexto de contato pode ter os seus valores e conceitos únicos diluídos quando rendidos em palavras e expressões da língua 
mais dominante. Esse é um problema difícil para as relações interculturais. (CORSON apud Boxer, 2002, p. 154) ${ }^{9}$

Logo, discussões que contemplem não só padrões culturais estrangeiros, mas também padrões da língua e cultura maternas são essenciais em aulas de língua estrangeira.

\section{Conclusão}

Neste artigo, procuramos estender a discussão apresentada por Agra e Burgeile (2010) nesta mesma revista. As autoras apresentaram uma análise bastante interessante a respeito da importância da integração da cultura nas aulas de LE. A nossa sugestão é de que essa integração seja feita de maneira crítica, levando o aluno a uma atitude (auto)reflexiva.

A esse respeito, há uma passagem significativa no artigo de Agra e Burgeile (2010) sobre os PCNs. Há um trecho onde se lê:

Os PCNs (BRASIL, 1998, p. 90-91, p. 97) mostram que a aprendizagem da LE vai muito além da aquisição de um conjunto de habilidades linguísticas. Ela aumenta a compreensão de como a linguagem funciona e desenvolve maior consciência sobre o funcionamento da própria língua materna. Ao mesmo tempo, ao promover uma apreciação dos costumes e valores de outras culturas, contribui para desenvolver a percepção do aluno da própria cultura por meio do contraste com as culturas estrangeiras. Essa compreensão intercultural promove, ainda, a aceitação das diferenças nas maneiras de expressão e de comportamento e, assim, aumentaria a autopercepção do aluno como ser humano e como cidadão. (AGRA; BRUGEILE, 2010, p. 22)

\footnotetext{
${ }^{9}$ Nossa tradução de: "If the two languages, along with the two cultural domains of which they speak, are not kept separate in a complex intercultural exchange, the weaker of the two cultures in that contact setting may have its unique values and concepts watered down when they are rendered into the words and expressions of the more dominant language. This is a thorny problem for intercultural relations".
} 
Em nossa opinião, para que o propósito dos PCNs seja plenamente atingido, é preciso que o contraste entre as culturas seja prática constante em sala de aula, uma vez que a simples apresentação de padrões culturais do outro grupo pode incorrer em uma desvalorização dos padrões próprios.

Boxer (2002) vai além e propõe que a compreensão intercultural esteja presente em todos os âmbitos da vida das pessoas:

A compreensão intercultural deve começar nas nossas famílias, bairros e comunidades. Nós podemos achar que os vizinhos da casa ao lado, nossos colegas, nossos professores ou colegas de escola têm maneiras diferentes de falar. Sem a compreensão dessas diferenças, nós poderemos não reconhecer oportunidades para estabelecer redes sociais, educacionais e profissionais que apoiem a comunicação bem sucedida e podemos, com isso, entravar o desenvolvimento de respeito e harmonia. ${ }^{10}$ (BOXER, 2002, p. 162).

Portanto, percebemos que essa compreensão mútua entre culturas distintas não beneficiaria apenas o encontro do nativo e do estrangeiro. Ela renderia bons frutos inclusive em encontros entre pessoas que convivem numa mesma nação e que, pelo menos em teoria, compartilham da mesma cultura ${ }^{11}$. A compreensão intercultural nos deixa mais sensíveis ao outro, sendo este outro um estrangeiro ou não.

Com referência ao exemplo utilizado no início do texto (tópico 1), quando da menção da situação vivenciada por White (1997 apud

\footnotetext{
${ }^{10}$ Nossa tradução de: "Transcultural understanding ought to start in our families, neighborhoods, and communities. We may find that the people next door, our colleagues or coworkers, our teachers or fellow students, have different ways of speaking. Without understanding these differences, we may fail to recognize opportunities to establish the social, educational, and workplace networks that support successful communication, thus hindering development of respect and harmony".

${ }^{11}$ Schröder (2008) discute conceitos de cultura e trata da dificuldade de se definir o intra e o intercultural.
} 
SPENCER-OATEY, 2005), poder-se-ia questionar os diferentes tipos de representações linguísticas - influenciadas pela cultura - que os interlocutores têm a respeito da expressao "had better". Poder-se-ia, também, argumentar que um turista, em visitas a países que não compartilham a sua língua materna (neste caso, o Inglês), deveria estar aberto aos novos sentidos emprestados à "sua" língua. Assim, é importante que não entendamos a interculturalidade em sala de aula como uma lista de DO's and DON'Ts em uma cultura diferente da nossa e, sim, como uma maneira de nos mostrarmos abertos ao desconhecido, mas sem, com isso, desvalorizarmos o conhecido e o familiar.

\section{Referências}

AGRA, Klondy Lúcia de Oliveira; BURGEILE, Odete. A necessária integração da língua e da cultura no ensino da língua estrangeira. In: Signum - Estudos da Linguagem, Londrina, v. 13, n. 2, p. 15-29, 2010. Disponível em: <http://www.uel.br/revistas/uel/index.php/signum/ article/view/6365/7019>. Acesso em: 5 abr. 2011.

AUER, Peter. Kontextualisierung. Studium Linguistik, v. 19, p. 22-47, 1986.

BENN-IBLER, Veronika (Org.). Interfaces Culturais Brasil - Alemanha. Belo Horizonte: Faculdade de Letras, 2006.

BLOCK, David. The social turn in second language acquisition. Washington, D.C.: Georgetown University Press, 2003.

BOAS, Franz. Race, language and culture. Toronto: Collier-Macmillan, 1982 [1940].

BOHUNOVSKI, Ruth. Ensinar alemão no Brasil: contextos e conteúdos. Curitiba: Editora da UFPR, 2011. [no prelo].

BOXER, Diana. Discourse issues in cross-cultural pragmatics. Annual Review of Applied Linguistics, v. 22, p. 150-167, 2002. 
BRASIL. Ministério da Educação e Cultura. Parâmetros Curriculares Nacionais: terceiro e quarto ciclos do ensino fundamental - língua estrangeira. Brasília: MEC/SEF, 1998.

BROWN, Penelope; LEVINSON, Stephen. Politeness: Some universals in language usage. Cambrige: Cambridge University Press, 1987.

CANAGARAJAH, A. Suresh. Resisting linguistic imperialism in English teaching. Oxford: Oxford University Press, 2003.

CASMIR, Fred L. A multicultural perspective of human communication. In: CASMIR, Fred L. Intercultural and international communication. Washington, D.C.: University Press of America, 1978. p. 241-257.

CORSON, D. World views, cultural values and discourse norms: the cycle of cultural reproduction. International Journal of Intercultural Relations, Mississippi, v. 19, p. 183-185, 1995.

COX, Maria Inês Pagliarini; ASSIS-PETERSON, Ana Antônio. O professor de inglês entre a emancipação e a alienação. Linguagem \& Ensino, Pelotas, v. 4, n. 1, p. 11-36, 2001. Disponível em <http:// rle.ucpel.tche.br/php/edicoes/v4n1/c_ana.pdf $>$. Acesso em: 10 abr. 2011.

EICHHEIM, Hubert; BOVERMANN, Monika; TESAROVÁ, Lea; HOLlERUNG, Marion. Blaue Blume. Livro do Curso. Campinas: Editora da UNICAMP, 2006.

FIENEMANN, Jutta Fienemann; REHBEIN, Jochen Rehbein. Introductions - Being polite in multilingual settings. In: HOUSE, Juliane House; REHBEIN, Jochen (Eds.). Multilingual communication. Hamburg Studies on Multilingualism 3. Amsterdam: Benjamins 2004. p. 223278.

GADAMER, Hans Georg. Wabrheit und Methode. Grundzüge einer philosophischen Hermeneutik. Tübingen: J. C. B. Mohr (Paul Siebeck), 1960. 
GÄRTNER, Eberhard; HERUTH, Maria José Peres et al. Contribuicõos para a Didáctica do Português Lingua Estrangeira: Akten der Sektion "Didaktik des Portugiesischen als Fremdsprache" des 4. Deutschen Lusitanistentages. Acatlán: Coordenación de Servicios Académicos, UNAM, 2001. v. 1.

GUMPERZ, John. Discourse strategies. Cambridge: Cambridge University Press, 1982.

HERDER, Johann Gottfried. Abhandlung über den Urspung der Sprache. Stuttgart: Reclam, 2002 [1772].

HOUSE, Juliane House; REHBEIN, Jochen (Eds.). Multilingual communication. Hamburg Studies on Multilingualism 3. Amsterdam: Benjamins 2004.

HUMBOLDT, Wilhelm von. Schriften zur Sprache. Hrsg. V. M. Böhler. Stuttgart: Reclam, 1992 [1836]. p. 30-207.

HYMES, Dell. Foundations in sociolinguistics: An ethnographic approach. Philadelphia: University of Pennsylvania Press, 1974.

LIDDICOAT, Anthony; CROZET, Chantal. Acquiring French interactional norms through instruction. In: ROSE, Kenneth; KASPER, Gabriele (Eds.). Pragmatics in language teaching. Cambridge: Cambridge University Press, 2001. p. 124-144.

JOHNEN, Thomas. Die Kennzeichnung von Handlungszielen durch Modalverben im Deutschen und Portugiesischen. In: GÄRTNER, Eberhard; HERUTH, Maria José Peres et al. Contribuições para a Didáctica do Português Lingua Estrangeira: Akten der Sektion "Didaktik des Portugiesischen als Fremdsprache" des 4. Deutschen Lusitanistentages. Acatlán: Coordenación de Servicios Académicos, UNAM, 2001. v. 1. p. 129-159.

KAY, Sue; JONES, Vaughan. American inside out upper-intermediate: Student's book. Oxford: MacMillan, 2003. 
MATURAMA, Humberto; VARELA, Francisco. A árvore do conhecimento - as bases biológicas do conhecimento humano. São Paulo: Palas Athena, 2004.

MÜHLMANN, Wilhelm E. Ethnologie als soziologische Theorie der interethnischen Systeme. Kölner Zeitschrift für Soziologie und Sozialpsychologie, Köln, v. 8, p. 186-201, 1956.

OKSAAR, Els. Zweitspracherwerb. Wege zur Mehrsprachigkeit und zur interkulturellen Verständigung. Stuttgart: Kohlhammer, 2003.

PALMER, Gary B. Connecting languages do world views. In:

Toward a theory of cultural linguistics. Austin: University of Texas Press, 1996a.

. Toward a theory of cultural linguistics. Austin: University of Texas Press, 1996b.

ROSE, Kenneth; KASPER, Gabriele (Eds.). Pragmatics in language teaching. Cambridge: Cambridge University Press, 2001.

SACKS, Harvey; SCHEGLOFF, Emanuel A.; JEFFERSON, Gail. A simplest systematics for the organization of turn-taking in conversation. Language, v. 50, n. 4, p. 696-735, 1974.

SAPIR, Edward. Culture, language and personality. Selected writings of Edward Sapir. Berkeley, Los Angeles: University of California Press, 1949.

SCHRÖDER, Ulrike. Conceitos metafóricos na comparação: uma contribuição à Landeskunde intercultural - dois exemplos da prática do ensino da língua estrangeira no contexto brasileiro. In: BENN-IBLER, Veronika (Org.). Interfaces culturais Brasil - Alemanha. Belo Horizonte: Faculdade de Letras, 2006. p. 49-69.

. Comunicação intercultural: uma desconstrução e reconstrução de um termo inflacionário. Cadernos de Linguagem e Sociedade, Brasília, v. 9, n. 1, p. 38-49, 2008. 
. Pragmática intercultural no ensino de alemão no Brasil. In: BOHUNOVSKI, Ruth. Ensinar alemão no Brasil: contextos e conteúdos. Curitiba: Editora da UFPR, 2011. [no prelo].

SPENCER-OATEY, H. (Im) Politeness, face and perceptions of rapport: unpackaging their bases and interrelationships. Journal of Politeness Research, n. 1, p. 95-119, 2005.

TAYLOR, Liz. International express: student's book pre-intermediate. Oxford: Oxford University Press, 2007.

THOMAS, J. Cross-cultural pragmatic failure. Applied Linguistics, v. 4, n. 2, p. 91-112, 1983.

WERTSCH, James. Voices of the mind. Cambridge, MA: Harvard University Press, 1991.

. Mind as action. Oxford: Oxford University Press, 1998.

WHITE, R. Going round in Circles. English as an international language, and cross-cultural capability. Paper prepared for the Cross-Cultural Capability Conference 1997, Leeds Metropolitan University, 15-16 December 1997.

WHORF, Benjamin Lee. Language, thought and reality. Selected writings of Benjamin Lee Whorf. Herausgegeben von John B. Carroll. Boston: Technology Press of M.I.T., 1956.

WIERZBICKA, Anna. Cross-culturalpragmatics. The semantics of human interaction. Berlin: Mouton de Gruyter, 2003. 